\title{
System of Logical Structures in Natural Science-Oriented Curriculum and its Effect on Teaching
}

\author{
https://doi.org/10.3991/ijet.v15i22.17155 \\ Renáta Bernátová, Milan Bernát, Janka Poráčová, Mária Zahatňanská, \\ Marta Mydlárová-Blaščáková, Mária Konečná, Andrea Kl’učarová ( $\left.{ }^{\varpi}\right)$ \\ The University of Prešov, Prešov, Slovakia \\ Andrea.Klucarova@smail.unipo.sk
}

\begin{abstract}
The system of logical structures in natural science- (biologically, ecologically- and physics-) oriented curriculum is defined as a set of features, which depict the main ideas of a certain topic. Basically, it is a unique model presenting the topic's key points. Graphical representation of the curriculum logical structure can be provided (implemented) as: a) traditional printed graphic form b) computer (virtual) form. When visualizing the logical structure system of natural science curriculum (including biologically-, ecologically- and physicsoriented school subjects), we mainly use the following structural components: Word maps, Applets, Orientation graphs (transport diagrams), Development diagrams, Venn diagrams, Structurograms, Sequence diagrams and others. This research paper includes a pedagogical experiment to verify the effectiveness of teaching with the use of graphic visualization of the curriculum logical structure.
\end{abstract}

Keywords - The system of logical structures, Biologically-, ecologically- and physics-oriented curriculum, Natural sciences

\section{Introduction}

A good scheme can replace a long article and a long speech as well.

M. G. Jaroševskij

The experience of teaching biologically-, ecologically- and physics-oriented curriculum indicates that having the knowledge of science facts and processes does not necessarily mean understanding the causality of the mechanisms hidden behind the theory. This causality issue refers to the proper logical structure of the curriculum (which finally results in more effective teaching biologically-, ecologically- and physics- oriented curriculum). In order to help the students, reach the level of comprehension, the authors of this paper suggest to integrate special graphic visualization of the curriculum logical structure system into the educational process (with active use of computer technologies). The research also includes a pedagogical experiment to verify the effectiveness of implementing the created graphic schemes of the curriculum logical structure into teaching. The results of this research have confirmed the correctness of authors' suggested solution to the causality problem. 
In this case, focus on the basic structure of school subjects is very important. It means that it is necessary to provide the students with less factual information, but to a greater depth and with a greater impact on the wider context. Pupils' and students' brains should not just store or accumulate plenty of misunderstood information. However, their knowledge should consist of a system of mutually interlinked information. In pedagogical terms, this form of knowledge is used to be called the "Union Philosophy". This is a quantitative point of view focused on the structure of school curriculum. On the other hand, a qualitative aspect gives the priority to formation of competences before knowledge acquisition [3].

Visualization of curriculum logical structure is a set of attributes representing the main ideas about a certain subject matter of each school subject. Moreover, it functions as a distinctive scheme or a logical model of curriculum. Graphic visualization of curriculum logical structure may be described in the following way: "By the term graphic form of curriculum logical structure visualization we will understand a graphical representation (visual mapping) showing the curriculum logical plurality of its strong points and the mental links among them (the curriculum logical system)".

In both levels, theoretical and practical one, a pedagogist called Bruner is the one who meets the requirements for curriculum logical structure and its impact on students' learning. Bruner argued that when students understand the schematic structure of the subject matter first, it will be easier for them to understand the whole topic afterwards [5]. Bruner's structuralism is based on several requirements. They include the requirement to structure the knowledge, to understand the fundamental structure of the subject and to create basic concepts, ideas or key words. Bruner's educational concept meets with the ideas of G. Brooks, who represent an educational stream emphasizing the development of thought processes in the concept of theoretical and practical synthesis [5]. The reference to Bruner's ideas applied into teaching specific technical subjects can be found in publication of Melezinek [5]. Melezinek proposed a system of teaching which, in German translation, was called A system of teaching emphasizing the structure of learning and logical connection in the curriculum (in the sense of Bruner's understanding of curriculum structure) [5].

\section{Structural Components of the Curriculum Logical Structure Visualization}

When visualizing the logical structure system of natural science curriculum (including biologically-, ecologically- and physics-oriented school subjects), we mainly use the following structural components: 2.1 Word maps, 2.2 Applets, 2.3 Orientation graphs (transport diagrams), 2.4 Development diagrams, 2.5 Venn diagrams, 2.6 Structurograms 2.7 Sequence diagrams 2.8 Special components of Intelligent computer graphics (so called Smart graphics) 2.9 Tables and graphs as well as some other components and their sets [3]. 


\subsection{Word maps}

A word map is a very useful strategy. Generally, it serves for illustrating the logical links between words. In addition, a word map is also used for visualizing the terminological hierarchy of the curriculum logical structure system (Fig.1).

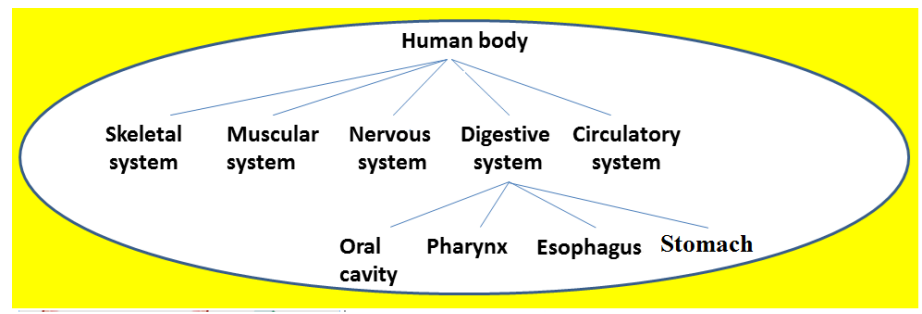

Fig. 1. Word map (print form), The human body systems (source - authors' own design)

Computer visualization of the system of curriculum logical structure (Fig. 2-Fig. 4) has several advantages in comparison to the traditional graphic form of visualization (which is based on hypertext). It allows us to:

- Visualize the logical links between the elements from different parts of curriculum;

- Establish the system of mutually interconnected subsystems of the virtually visualized system of curriculum logical structure having the form of integrated schemes.

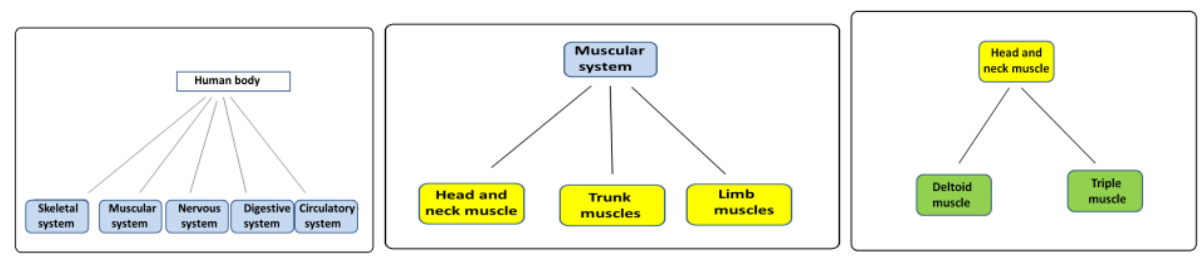

Fig. 2. Word map (electronic form - hypertext) - The human body systems (authors' creations).

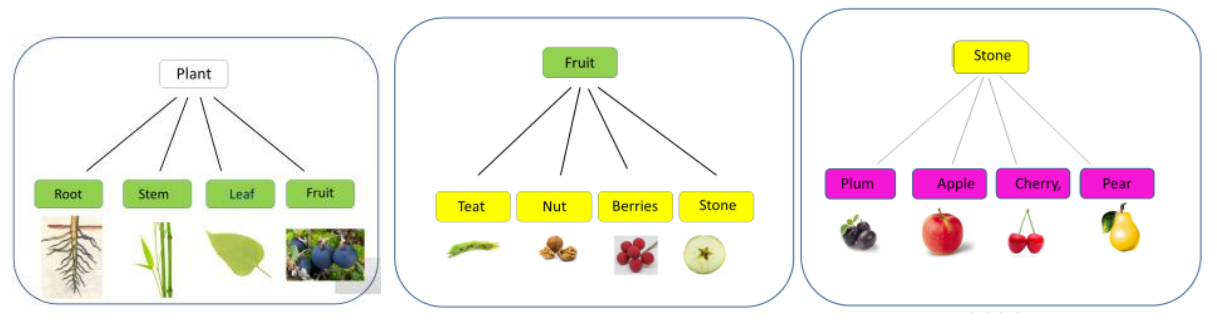

Fig. 3. Word map (electronic form - hypertext) - Plants. (source- authors' own creations) 


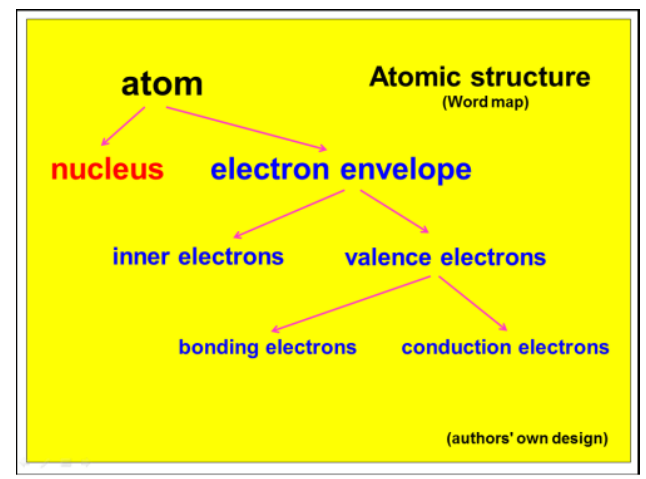

Fig. 4. Word map (printed form), Atomic structure (source - authors' own design)

\subsection{Applets}

A structural component has a very special position among the other listed components for visualization of curriculum logical structure. In fact; this component incorporates all other types of visualizing components. In other words, a structural component is not just one particular component, but a complex unit consisting of several subcomponents. At this place it is equally important to say that applet is a single-purpose program (especially educational one), which was developed on a platform known as modern elements of intelligent computer graphics [8] The issue of creating and applying applets into teaching science subjects is extensively processed and detailed in publications [3] and [8], written by the authors of this paper.

\subsection{Orientation graphs (transport diagrams)}

Orientation graphs are particularly useful for illustrating the curriculum logical structure resulting from the transport-like nature of the phenomenon. Its graphic form is represented by the oriented line (symbolizing an arrow) starting from the source and leading towards the target place of transport. The area along this oriented line usually informs about the key subject-matter of a particular transport mechanism (e.g. chemical equation) or transported particles (such as their movement, time relations of transport - including shifting and its causality over time, then slowing down, accelerating or shifting the curve development over time). (Fig.5 - Respiration on plants).
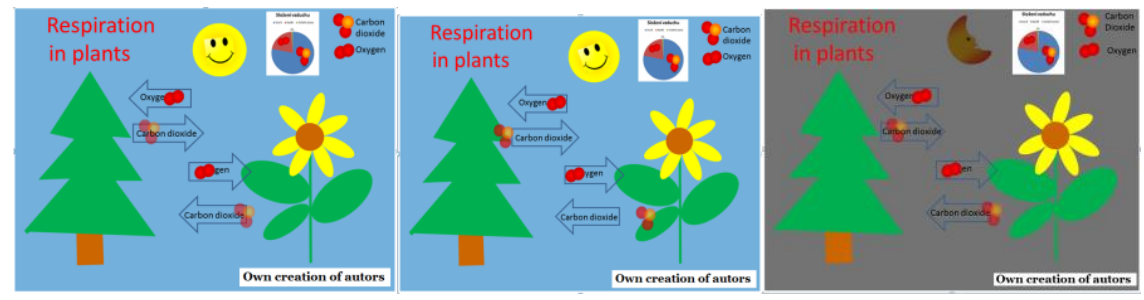

Fig. 5. Orientation graphs (transport diagrams) - Respiration in plants 


\subsection{Development diagrams}

In development diagrams, a graphic representation consists of decision blocks. They contain conditions for branching as well as for orientation of lines (arrows) entering into each decision block and exiting from it (branching alternatives).

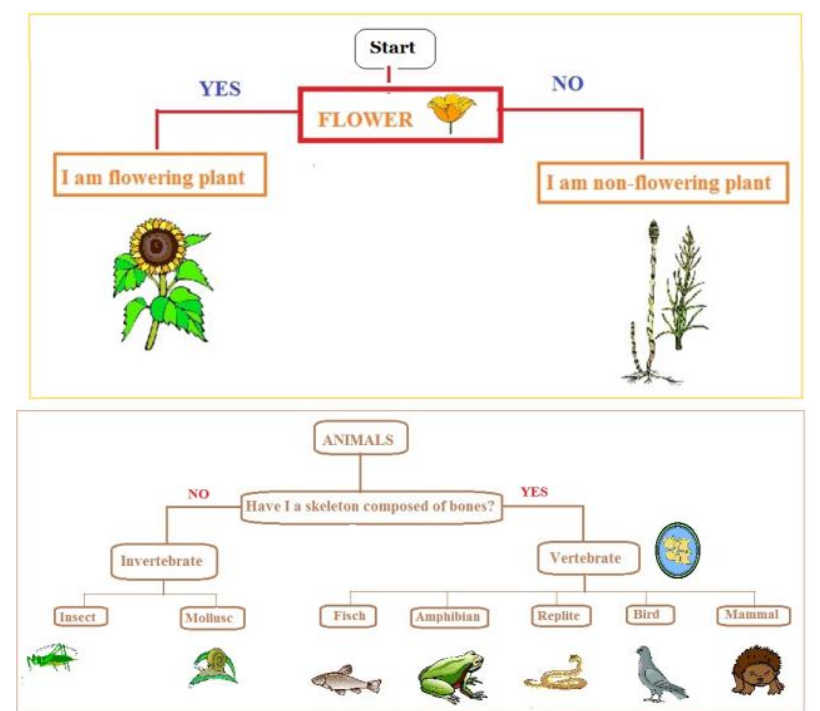

Fig. 6. Development diagrams (printed form) - The animal kingdom, flowering plants (authors' own creations).

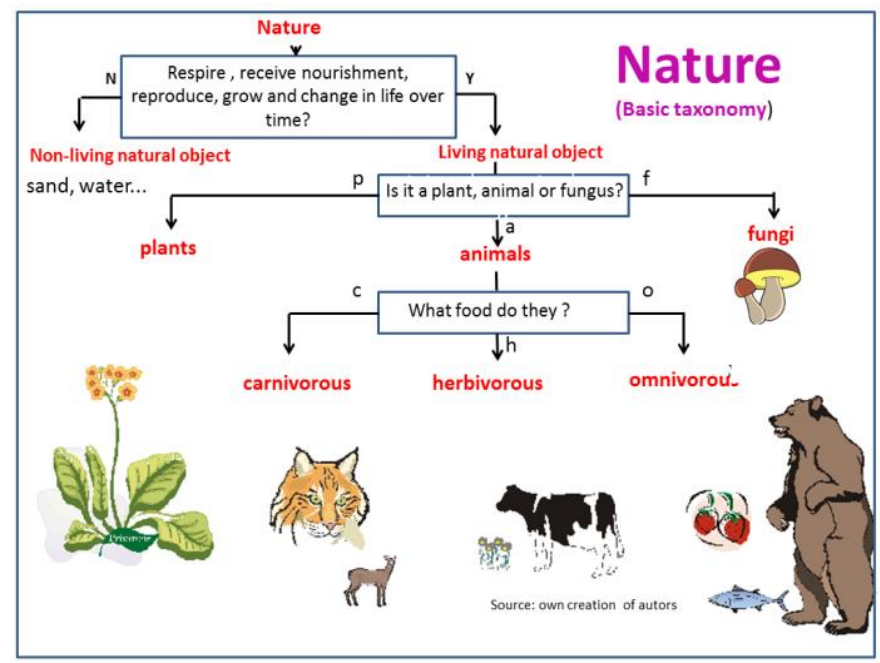

Fig. 7. Development diagram (printed form) - Nature (source - authors' own creations). 


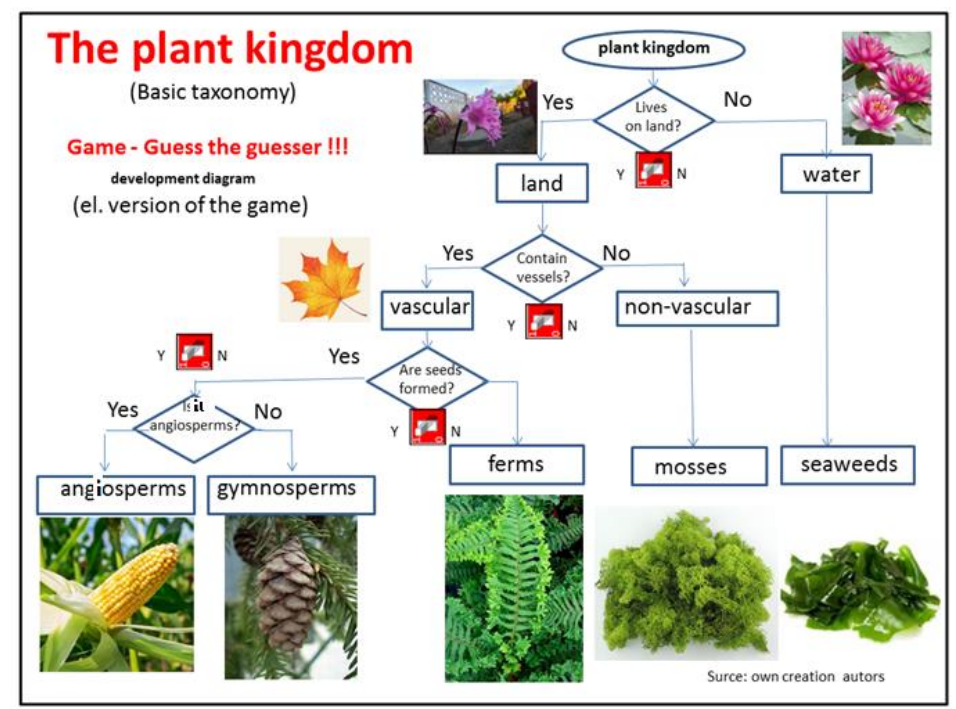

Fig. 8. Development diagram (electronic form- Java) - The plant kingdom (source - authors' own creations).

\subsection{Venn diagrams}

Venn diagrams can be described as graphic visualizations consisting of a set of pictures and symbols. They illustrate the key points of a certain study material and evoke logical assumptions. Furthermore, Venn diagrams offer a very convenient possibility of combining them with other types of visualizing components. Especially, the combination of Venn diagram and development diagram is very suitable and also recommended Fig. 9).

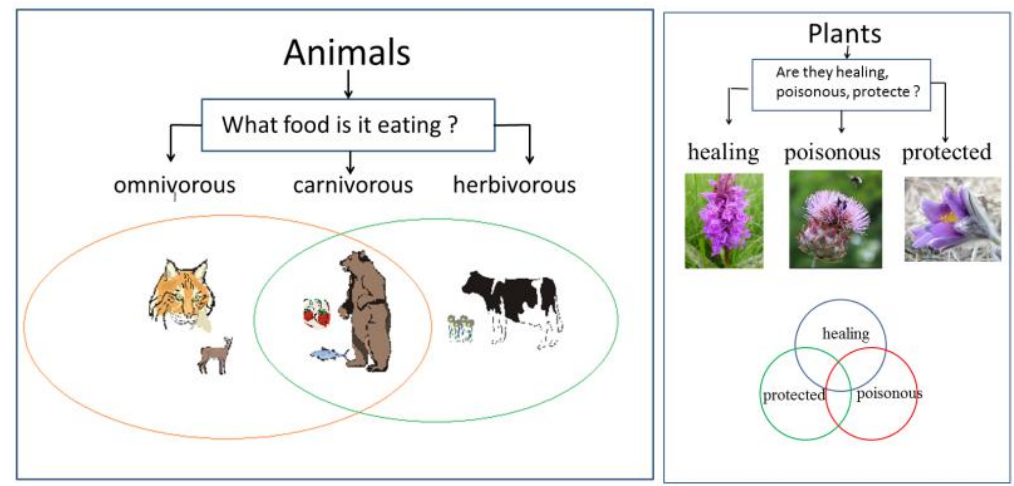

Fig. 9. Combination of Venn and development diagrams

(Animals, Plants- healing, poisonous, protected) (source - authors' own creations). 


\subsection{Structurograms}

Structurograms represent a "binding unit, functional basis, bond or a pillar" the curricular structures. They give the curriculum a "systematic breath", but more importantly, a "skeleton" consisting of a global knowledge structuring. It covers the curriculum thematic units from different school grades. This means that structural elements are not isolated pieces of information, but they form a complex system of interlinked facts). Additionally, they can be understood as a simplified variant of the flat block diagram in its graphical form. In this diagram, every single block usually has a rectangular form (circles, triangles, and other geometrical types are less common). The lines between the blocks indicate their relationships. A horizontal line is a sign of equivalence while the vertical line usually means inclusiveness. In general, the term stucturogram refers to the mutual interconnection between the set of blocks and the set of orientation lines.

Structurograms (dealing with anatomical topics)

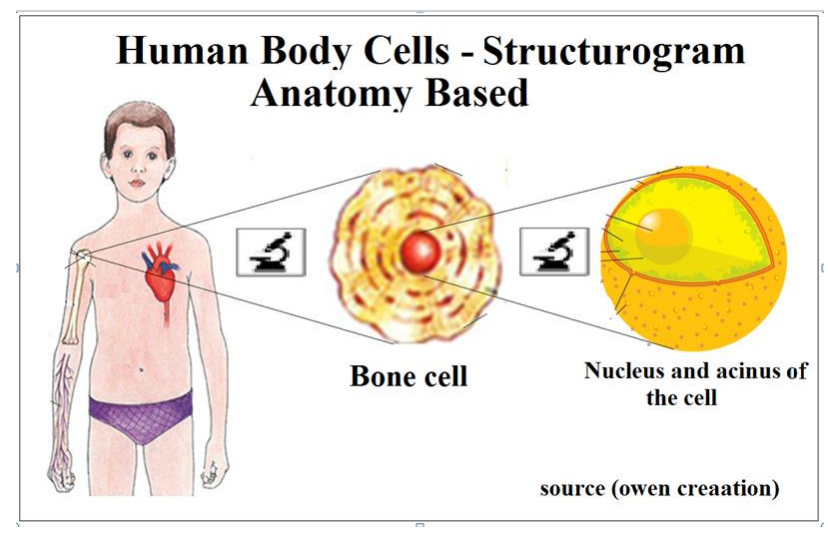

Fig. 10.Printed form of structurogram (dealing with anatomic topics) - Human Body Cells.

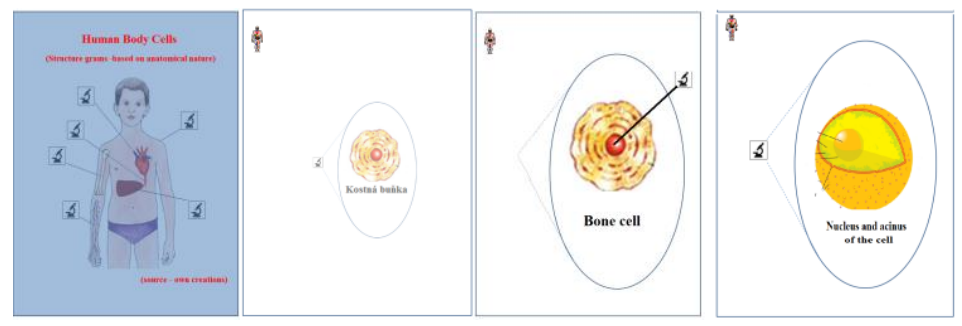

Fig. 11.Electronic form (hypertext) of structurogram (dealing with anatomic topics) - Human Body Cells (source - authors' own creations). 


\section{Structurograms (dealing with physiological topics)}

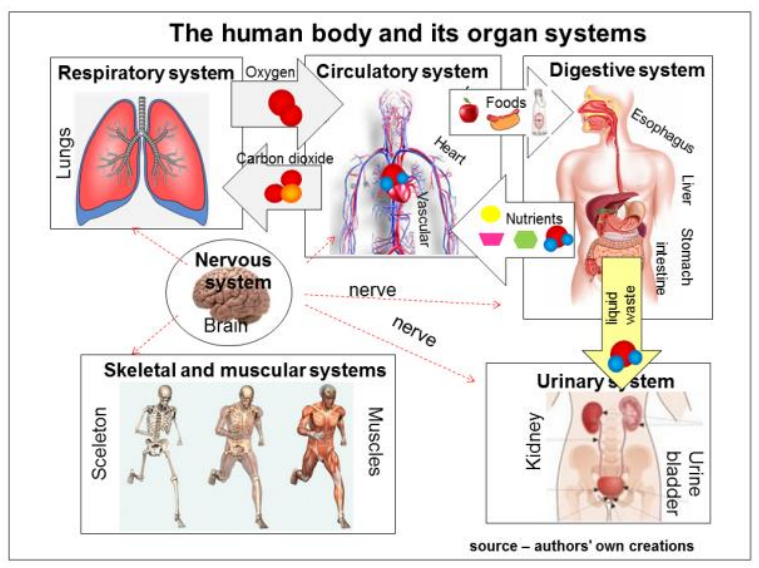

Fig. 12.Structurograms (printed form- - The human body and its organ systems

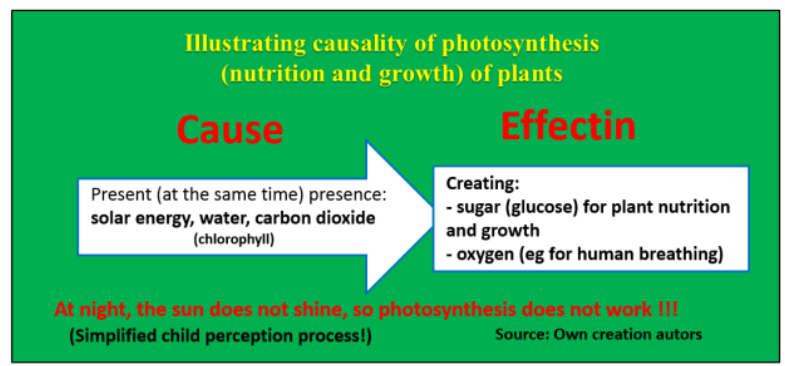

Fig. 13.Structurograms - Illustrating causality of photosynthesis - Cause - Effectin

Structurograms of the type - Cause/Effectin (e.g. Fig. 13) can be considered as a special form of structurograms, emphasizing in particular the causality of scientific processes and phenomena.

Based on the systemic understanding of the biochemical system, which is photosynthesis (and its imaging by the structural program), its didactic application primarily emphasizes the causality of biochemical reactions (causal connection in the context of cause-effect). Last but not least, the specification of inputs and outputs to and from the biochemical system, but also the specificity of the running of biochemical processes of photosynthesis - (photosynthesis during the day and night, photosynthesis in individual seasons, etc.).

Note: In recent years, biophysical and biochemical processes from modeled (and displayed) on the platform of regulatory circuit theory can be found in some textbooks of physiology [4]. From the didactic point of view, these are very illustrative teaching aids, which can also be included among the structurograms (dealing with physiological topics). The possibility of such modeling stems from the biocybernetic nature of the regulation of biophysical and biochemical processes and phenomena. 


\subsection{Sequence diagrams}

Sequence diagrams (Fig.14), Which can be used for the creation of anchors and crosswords, etc.

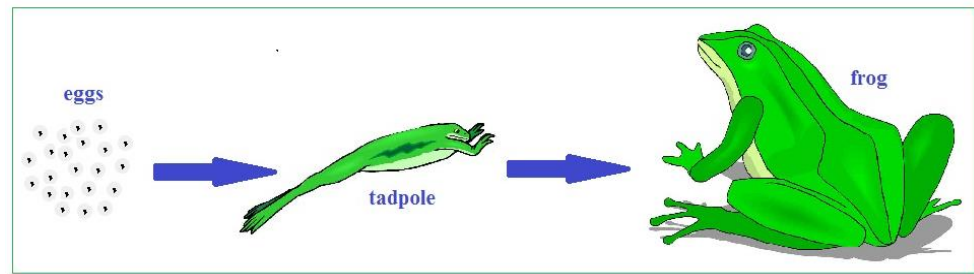

Fig. 14.Sequence diagram - Life cycle of a frog (printed form)

\subsection{Special components of Intelligent computer graphics (so called Smart} graphics)

These components are the carriers of computer interactivity as well as computer animation and simulation (e.g. websites, hypertexts, audio commentaries, drag and drops and many others).

\section{Realization (implementation) Forms of the Curriculum Logical Structure Visualization}

Graphical representation of the curriculum logical structure can be provided (implemented) as:

a) Traditional printed graphic form - e.g. study materials (worksheets), wall pictures (posters), form of simple transparency films, form of complex transparency films, use of magnetic boards, film slides, videotapes.

b) Computer (virtual) form - including multimedia educational programs, hypertexts, websites, audio commentaries.

\section{The Research - Pedagogical Experiment to Verify the Effectiveness of Implementing the Created graphic schemes of the Curriculum logical structure into Teaching Science subjects}

The authors of this paper created a new experimental teaching system (hereinafter referred to as NESVL). We have created a database of graphically visualized logical support for the curricular thematic units (Table 1, Table 2). Moreover, we designed an experimental teaching system (referred to as NESVL) which is based on applying the visualized logical support into the university course structure. We have chosen one 
particular course called Elementary Science for future teachers of 1st - 4th graders at primary schools. It is focused on teaching and learning biologically-, ecologically- and physics- oriented curriculum.

\subsection{Aims and initial hypotheses of the research}

The main aim of this research was to explore the possibility of applying the visualized logical support of the curriculum structure system in order to increase the effectiveness of the educational process.

NESVL's designed and implemented platform was based on using the media containing the graphic visualization of the logical structure of biologically-, ecologicallyand physics-oriented curriculum (logical support) in school environment. In addition, it was supposed to be combined with Socratic questioning during the teaching-learning process (in the phase of revision, fixing, and refining the subject). The basis (essence) of NESVL method, in a form it was planned and designed, can be characterized as follows (Table 1, Table 2):

Table 1. Principal essence of pedagogical experiment

The goal of the pedagogical experiment: Visualization of the Logical Structure of Biologically-, Ecologi cally- and Physics-oriented Curriculum and its Application in Teaching in order to Increase the Level of Understanding the Causality (Coherence of Cause and its Effect) in the Curriculum (As a consequence, we also expect to increase the teaching effectiveness of teaching science subjects)

The experimental group (Experimental way of teaching

The control group (Traditional way of teaching)

Input didactic test (checking the statistical equivalence groups)

Experimental group was taught with the use of media The traditional way of teaching (former traditional containing graphically visualized logical support methods)

(visualization of the logical structure of biologically

Output didactic test (detection and comparison of the effectiveness of teaching)

Table 2. Thematic Units Being Taught During The Ped. Experiment

I. DIVERSITY OF NATURE AND ITS KNOWLEDGE, II. BREATHING AND NUTRITION OF

PLANTS AND FUNGI, III. WATER CYCLE, IV. Physics around us, V. Technics, technology and US

Theoretical knowledge as well as empirical experience presented in the theoretical part of this paper led us to defining 12 hypotheses. Here we mention only the most important ones (in terms of purpose): 
- H1: The students attending a university course called Elementary Science for future teachers of 1st - 4th graders at primary schools taught by NESVL method will achieve higher performance in cognitive learning (in the final didactic test) at the end of pedagogical experiment in comparison to students taught in a traditional way.

- H2: The students taught by NESVL method will achieve higher performance in cognitive learning (in each of the monitored parameters (remembering, understanding and applying information into practice - by Niemierko) at the end of pedagogical experiment in comparison to students taught in a traditional way.

- H3: The students taught by NESVL method will evaluate the experimental teachinglearning process positively in comparison to students taught in a traditional way.

- H4: The students taught by NESVL method will have a better attitude towards this particular school subject (Elementary Science for future teachers of 1st - 4th graders at primary schools) in comparison to students taught in a traditional way.

- H5: The teachers using the NESVL method will say at the end of pedagogical experiment that this system increases the effectiveness of the teaching-learning process of university course called Elementary Science for future teachers of 1st - 4th graders at primary schools.

\subsection{Selection of research samples and the research methods}

The research was done on a research sample consisting of 366 students enrolled into university course called Elementary Science for future teachers of 1st - 4th graders at primary schools. It was conducted by The University of Prešov in Prešov. The research was done during the summer semester of academic year 2017/2018.

By analysing the variance at a significance level of 0.01 (F-test), we checked the statistical equivalence of the sample sets in the following equivalence indicators: the overall benefit of NESVL method for the pupils students and the benefit of the experimental subject called Elementary Science for future teachers of 1st - 4th graders at primary schools at the end of the last completed year, the initial didactic test and the entry questionnaire for students. The analysis showed that there was no statistically significant difference in either of the indicators. For this reason, the selected groups could be considered equivalent.

We used the following pedagogical and pedagogically-psychological research methods: 1. Traditional pedagogical experiment - the main method, 2. Didactic tests - to verify the hypotheses $\mathrm{H} 1, \mathrm{H} 2, \mathrm{H} 3, \mathrm{H} 4, \mathrm{H} 5, \mathrm{H} 8,3$. Questionnaire method - to verify hypotheses H6, H7, H9, H10, H11, H12, 4 Interview - to verify hypotheses H6, H7, H10, H11, H12, 5. Observation 6. Statistical methods of processing the research results - for statistical verification of research hypotheses.

\subsection{Traditional pedagogical experiment - The main method}

We have performed a two-group pedagogical experiment. One group - experimental group (consisting of students attending experimental lessons) was taught by the NESVL method while the other one - known as the control group (consisting of students attending traditional lessons) was taught by traditional teaching methods. 
The independent variable is, in this case, represented by the method of teaching. When teaching experimental group, a NESVL method was used. However, in the control group, the traditional teaching methods were used.

In our experiment, the students' final performance was a dependent variable. It concerns remembering and memorizing the knowledge, understanding the scientific information and its application into practice and finally, both - teachers' and students' attitudes towards the educational process. As it comes to validity and reliability of the experiment, it was extremely important to respect some special variables, such as students' individual personalities, teachers' personalities, learning objectives and the subject matter of each topic, time of teaching and teaching methods.

\subsection{Method of using the questionnaire}

The goal of the questionnaire research method was to obtain and evaluate information: - about the students the teachers' and students' opinions on the NESVL method (from the teachers' and learners' point of view).

\subsection{The major experimental research analysis results}

The statistical interpretation of the research analysis results is quite concise as a matter of fact that the graphs are eloquent enough - (Fig. 15 and Fig. 20). They include digitally processed data related to the values from the questionnaire as well as the basic characteristics of statistical ensembles arranged into the tables. As we find them sufficiently descriptive, we do not provide any additional verbal explanations - (Tab 3). For easier and more targeted analysis, we analysed the output didactic tests from the point of view concerning the level of educational goals (in accordance with the Niemierko's taxonomy of educational goals). Output didactic tests were divided by experts into the several subtests (Fig. 15 - 20): Subtest N1: Memorizing the information, Subtest N2: Understanding the information (Knowledge), Subtest N3: Application of information (use of knowledge). 


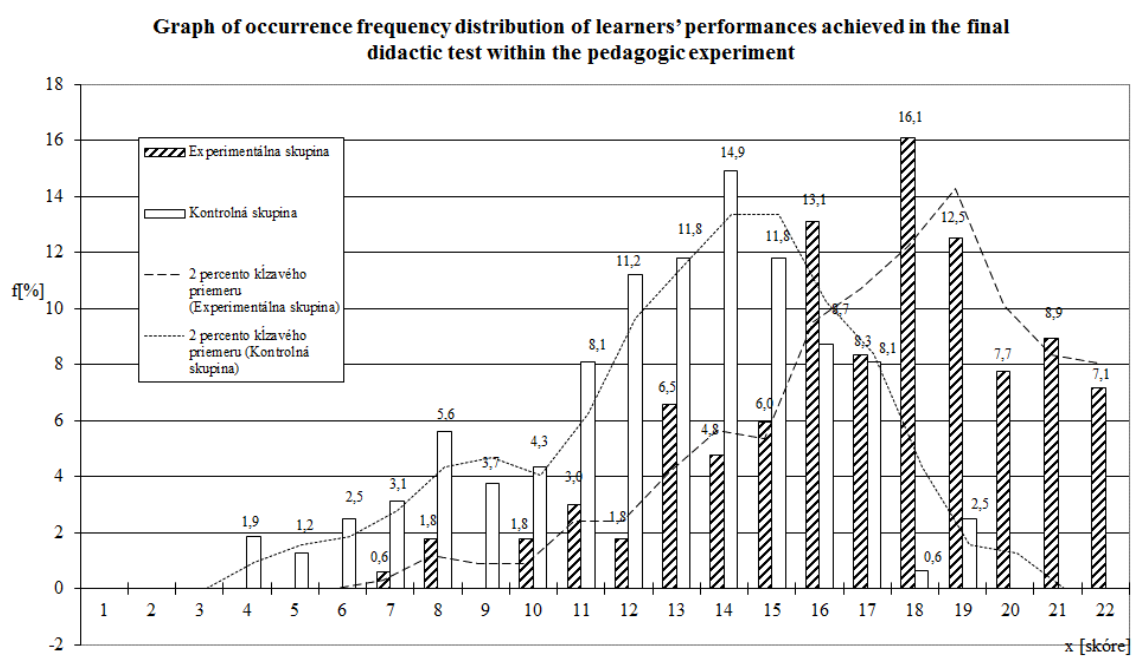

Fig. 15.Frequency distribution of learners' performances achieved in the final didactic test within the pedagogical experiment

Table 3. Descriptive and Inductive Statistics
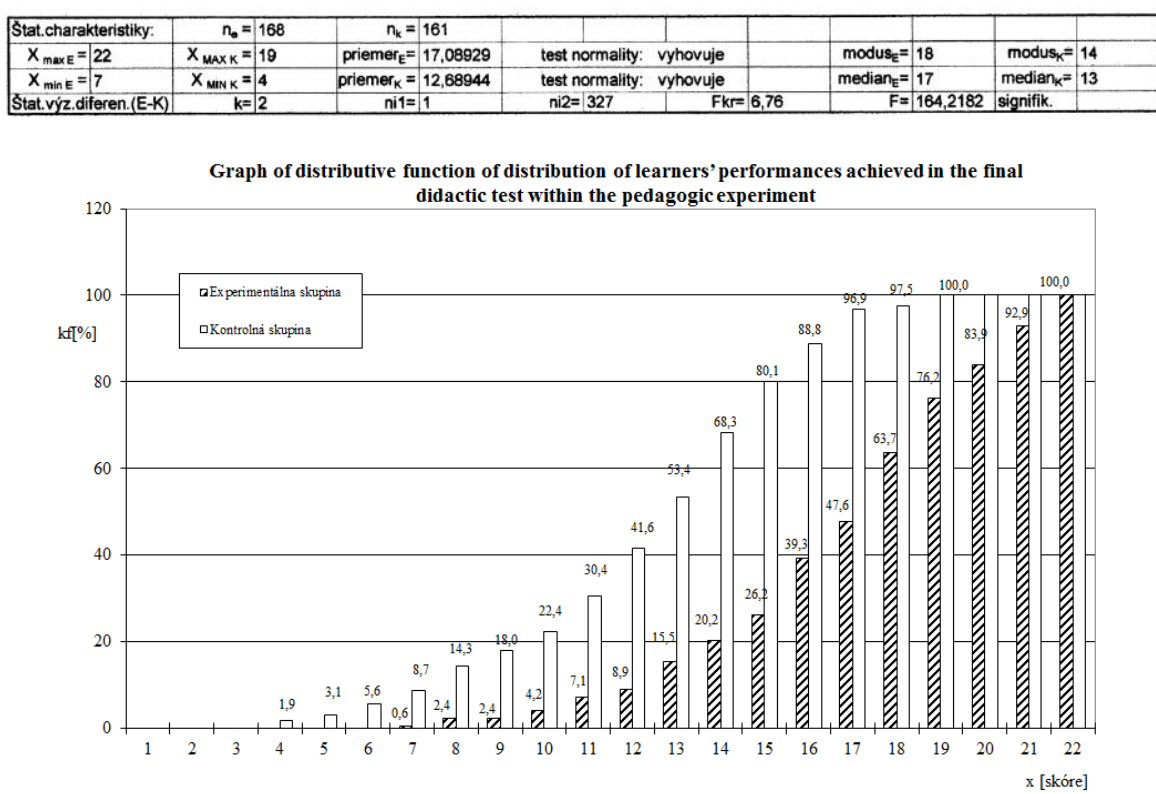

Fig. 16.Distributive function of learners' performances (scores) achieved in the final didactic test within the pedagogical experiment 


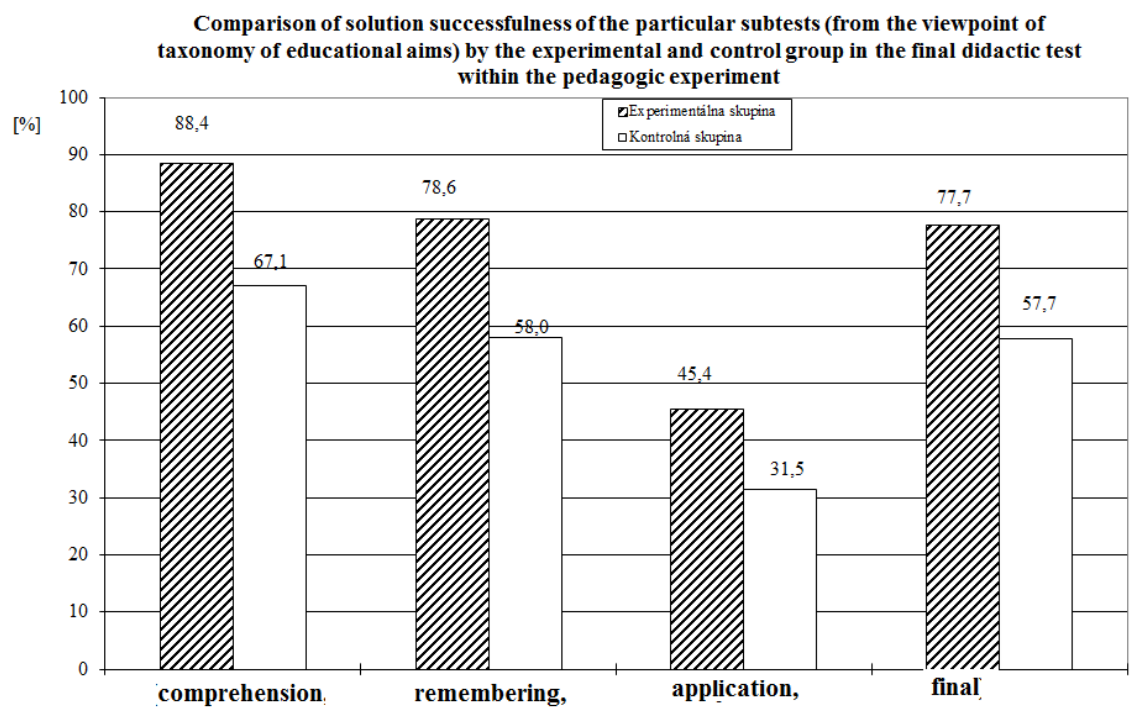

Fig. 17.The comparison of the success rate of individual subtests assessing the learning objectives (comprehension, remembering, application) and final test result of the experimental and a control group in the final didactic test

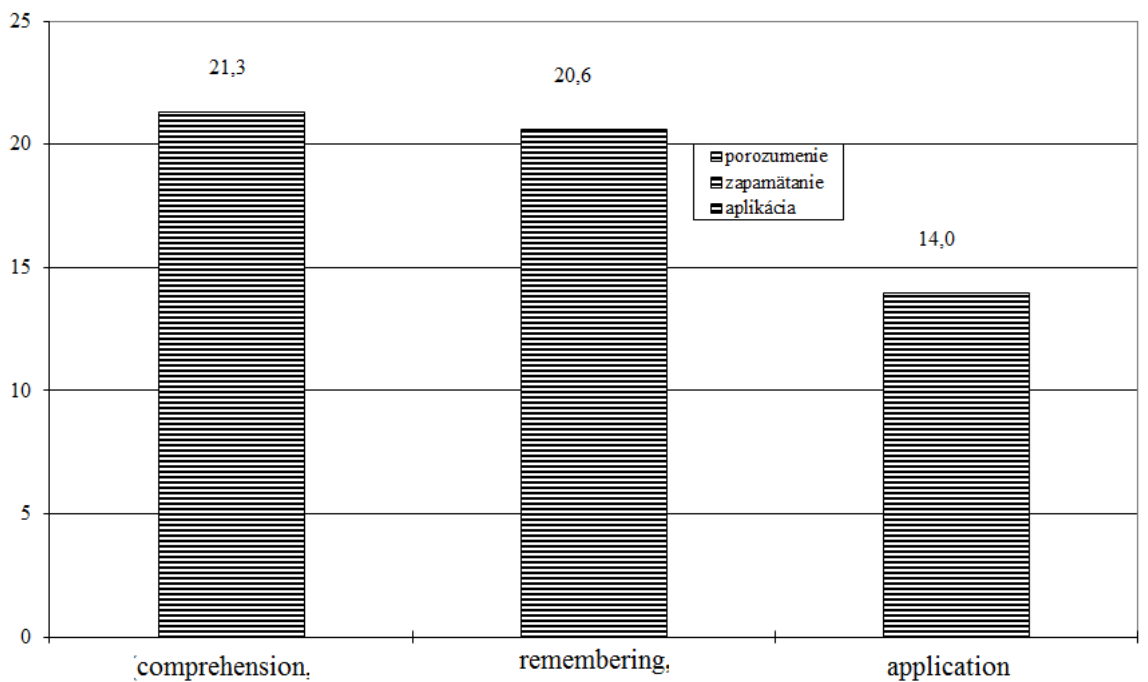

Fig. 18.Differences in Comparison of the success rate of individual subtests assessing the learning objectives (comprehension, remembering, application) and final test result of the experimental and a control group in the final didactic test

From the viewpoint of relations between the terms, the didactic tests were divided into the following independent subtests [3]: functional relations, purpose relationships, relationships of inferiority, revealing the context in concepts, multi-person 
relationships, exclusion of terms that do not belong to the given logical word group, selection of terms according to a particular criterion, definition of terms according to their characteristics, revealing the meaning of scientific terms.

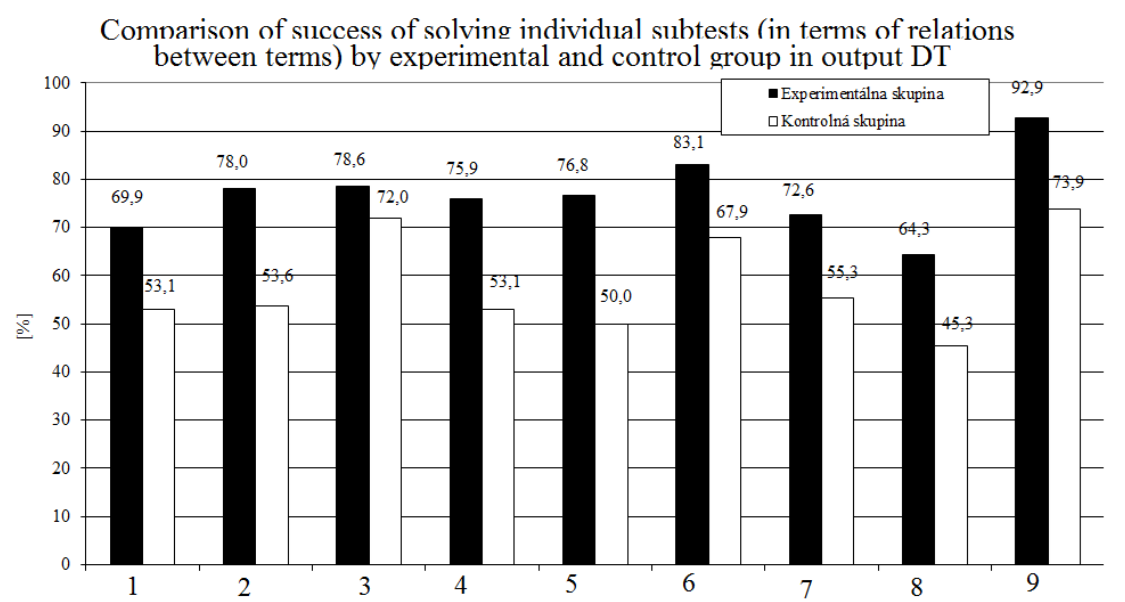

Fig. 19.1. functional relationships 2 . inferiority relationships 3 . revealing the connection between concepts, 4 . multi - person relations, 5. exclusion of terms, 6 . choosing the terms according to a given criterion, 7 . defining the terms according to characteristic features 8. exclusion of terms, 9. revealing the meaning of terms

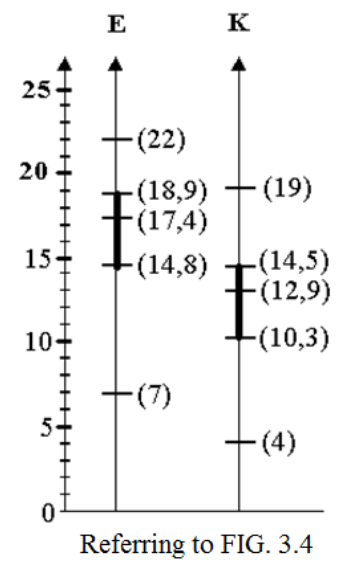

Fig. 20.Graphical display of quartile analysis results

\subsection{Research results}

Based on the statistical verification of the hypotheses of our research, we can present the following research results: 
a) Descriptive statistics (Fig. 15 - Fig. 20): There is a statistically significant difference between the performance of students taught by NESVL method and the students taught in a traditional way. Both groups of students took a didactic input and output test concerning the science-oriented topics from the university course of Elementary Science for future teachers of $1 \mathrm{st}$ - 4th graders at primary schools. Students working with the NESVL system during our pedagogical experiment have achieved higher performances in cognitive learning when compared to students taught traditionally. Before the end of each experimental lesson we focused on mapping educational aims (like remembering, comprehension and applying information).

The students of the experimental group achieved a $77.68 \%$ success rate in the didactic test of Elementary Science for future teachers of 1st - 4th graders at primary schools while the students of the control group $57.68 \%$ (Fig. 17). These results show that the differences in the individual subtests success rates between the experimental and control group are as follows: $20.6 \%$ in remembering; $21.3 \%$ in comprehension; $14 \%$ in application and $20 \%$ in final didactic test application. All results are in favour of the experimental group (Fig. 18). In addition, students working with NESVL system have evaluated the course of the experimental teaching process more positively than traditional learners. Teachers teaching at with the use of NESVL method have stated at the end of the experimental period that NESVL method increased the effectiveness of the teaching-learning process of the experimentally-created university course. Teachers have also expressed their positive attitude towards the NESVL method.

b) Inductive statistics (Table 3): The statistical significance of the performance difference between the experimental and the control group was achieved in the final didactic test and is presented globally in the Table 3, part about Inductive statistics. It was done by the analysis of variance $-\mathrm{F}$ test. Calculated $\mathrm{F}$ was of the value 164.2 and calculated $\mathrm{Fkr}=6.76$. Since $\mathrm{F}>\mathrm{Fkr}$, we can say that in students' ${ }^{\prime}$ performances achieved in the final didactic test there is a statistically significant difference between the experimental and control group. (The significance level is 0.05). The interpretation of the subtest results N1 (remembering), N2 (comprehension), N3 (application) is analogical to the previous. (See Table 3. - Descriptive and Inductive statistics).

Finally, we dare to say that the proposed experimental teaching system called NESVL method appears to be more effective than the traditional one student participating in the experiment showed better performances in cognitive learning as well as in all the other observed parameters (remembering, comprehension, application).

\section{Conclusion}

Nowadays, with the unprecedented increase of information amount resulting from the dynamic increase in knowledge in almost every field of science, it is important especially to look for teaching methods of the broad-range character as it comes to age of the learners, but also in the level of the teaching management, as well as, sequencing, application possibilities, flexibility, modularity, and finally, the causality of 
phenomenon-oriented knowledge. They are non-formally referred to as teaching systems aimed at highlighting the curriculum structure [3].

How did the NESVL method do in such a viewpoint? The overall analysis of using this modern innovative teaching method (based on the logical system of learning) in school environment shows that it has good perspectives for being fully implemented into the educational process. Moreover, the analysis proves that the NESVL method is a valuable tool for increasing the effectiveness of teaching at the Faculty of Education. In addition, the research provides us with a clear evidence of achieving positive qualitative changes in the students' knowledge structure by means of the NESVL method. At the end of our pedagogical experiment, we found out that the students did not only memorize the knowledge, but also deeply understand it Furthermore, the students from the experimental group were capable of better applying the theoretical knowledge into practice than students attending traditional lessons. The most encouraging fact is that the NESVL innovative teaching method can be implemented into the teaching-learning process without any radical transformation of the traditional teaching system as it was fully mentioned in [3]. In our opinion, it is its biggest advantage.

In addition, the participants of this research consider the NESVL method much more attractive and motivating than the traditional way of teaching. What is more, the members of the experimental group stated that they had been looking forward to being taught with the use of NESVL method.

Based on this research results, we will analyse the NESVL method more in the future. We will focus on the complex viewpoint on the expected inputs and obtained outputs, as well as their ratio. The necessary inputs for the realization of NESVL method will be examined in the following levels: level of equipment, level of the changes needed to be done in the traditional system of teaching and the personal level concerning all participants of the educational process.

The model of graphically visualized logical support of the educational structure system we have designed, modifies the traditional structure of a certain thematic unit lecturing block over the average time span, of one lesson. It is usually the last lesson from the block of the thematic unit teaching. The "radicality" of this intervention is even milder if one realizes that some teachers also try to "summarize the interpretation" during a traditional lesson. But not all teachers do this, not even systematically, not at every school subject and not to necessary depth and width. NESVL method eliminates the lack of teaching materials and help with correct methodical integration of these efforts. A similar issue can be found in [6], [7], [9], [10].

\section{Acknowledgement}

This research paper is published (and financially supported) as the output of the project - KEGA, No. 018PU-4/2018 Innovation of methods and forms of teaching the subject of biochemistry. Books will be used for teaching internal students. 


\section{$7 \quad$ References}

[1] Bernátová R. (2019): On Increasing Efficiency in Teaching Technical and Natural Sciences by Means of JAVA Applets II. (Experimental Research), Journal of Technology and Information Education, vol. 1 issue 1, 2019

[2] Bernát, M. (2005): Visualization of some electro-physical process through computer for didactic purposes and its application in teaching electrotechnical subjects. $\mathrm{PhD}$. Thesis, $\mathrm{PdF}$ UKF Nitra 2005

[3] Bernátová R. (2019): Proposal for use of visualization of logical foundation of subject matter and its ways of application in connection with elevating effectiveness of a teaching process., Rokus 2019, Prešov, ISBN 80-89055-08-7.

[4] Kittnar, Otomar, (200): Fyziologické regulace ve schématech. Praha: Grada Publishing, spol. s r.o., 2000, 1. vyd. 228 s.

[5] Melezinek A. (1986): Ingenieurpädagogik: Praxis der Vermittlung technische Wissens techn. Wissens. Wien, New York, Springer, 1986.

[6] Huiping Guo, Lin Zhu, Fengxin Yan (2016): Research on Key Techniques for Enginery Teaching Platform Based on Computer Dynamic Simulation Technique in, International Journal of Emerging Technologies in Learning (iJET) - eISSN: 1863-0383, Vol 11, No 08 (2016) page 54-58. https://doi.org/10.3991/ijet.v11i08.6049

[7] Chang Pan (2016): Design and Application of Multi-screen VR Technology in the Course of Art Painting International Journal of Emerging Technologies in Lear-ning (iJET) eISSN: 1863-0383, Vol 11, No 09 (2016) page 56-60. https://doi.org/10.3991/ijet. v11i09.6126

[8] Bernátová, R and others (2020): Elements of Smart Computer Graphics - A Potential Basis for New Experimental Method of Teaching and Learning, International Journal of Emerging Technologies in Learning (iJET) - eISSN: 1863-0383, Vol 15, No 13 (2020) page 221-237 https://doi.org/10.3991/ijet.v15i13.13481

[9] Yanqun He (2015): Application of Panoramic Image Technology in Distance Teaching System, International Journal of Emerging Technologies in Learning (iJET) - eISSN: 18630383, Vol 10, No 6 (2015) page 27-31 https://doi.org/10.3991/ijet.v10i6.4848

[10] Turek, I. (2016): Didaktika. Bratislava: Wolters Kluwer. ISBN: 978-80-8168-004-5

\section{Authors}

Renáta Bernátová, was born in Prešov, Slovakia, in 1966. She was awarded the RNDr. degree from the Faculty of Natural Sciences of UPJŠ in Košice, then Doc. and PhD. degrees from the UKF in Nitra. Email: renata.bernatova@unipo.sk

Milan Bernát was born in Košice, Slovakia, in 1959. He was awarded the Ing. (MSc) engineer's degree in FEI TU in Košice in 1983. He gained the PhD., Doc. from UKF Nitra in 2001 (thesis [1]).

Janka Poráčová, dean of the Faculty of Humanities and Natural Sciences of Prešov University in Prešov, Slovak republic. She received a MVDr. degree (D.V.M. - Doctor of Veterinary Medicine - in 1985), Doc. degree (2001), Prof. degree (2015).

Mária Zahatňanská, was born in Prešov, Slovakia, in 1963. She was awarded the PaedDr. degree from Prešov University in Prešov, Faculty of Humanities and Natural Sciences in Prešov, Slovak republic (2000). PhD. (2007). 
Mária Konečná, was born in Vranov nad Topl'ou, Slovakia, in 1982. She was awarded the RNDr. degree and PhD. degree from the Faculty of Humanities and Natural Sciences of Prešov University in Prešov, in 2017.

Marta Mydlárová-Blaščáková, was born in Levoča, Slovakia, in 1983. She was awarded the RNDr. and PhD. degrees from the Faculty of Humanities and Natural Sciences of Prešov University in Prešov.

Andrea Kl'učarová, (corresponding author), is a postgraduate student at Prešov University. She received her master's degree (Mgr.) in Teaching Physics and her engineer's degree (Ing.) in Physical Engineering of Progressive Materials. Email: andrea.klucarova@smail.unipo.sk

Article submitted 2020-07-19. Resubmitted 2020-08-08. Final acceptance 2020-08-10. Final version published as submitted by the authors. 